\title{
Review on the Management of Primary Congenital Glaucoma
}

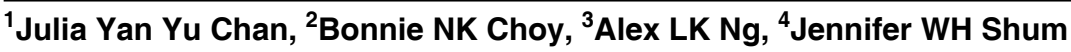

\begin{abstract}
Despite being documented in medical history from over 2400 years ago, primary congenital glaucoma (PCG), being a disease with low incidence rate, remains a challenge to ophthalmologists.

The article provides a broad overview on the pathophysiology and diagnostic approach to PCG with major emphasis on the treatment options of PCG. While reviewing on the wellestablished treatment options, namely goniotomy, trabeculotomy and combined trabeculotomy-trabeculectomy, emphasis has also been made to recent updates on secondary treatments: trabeculectomy, antimetabolites, glaucoma-drainage devices and cyclodestructive procedures.

It is, however, important to note that the rarity of PCG places limitations on study design, most studies are, thus, retrospective, nonrandomized and have different definitions of surgical success. Ophthalmologists need to interpret the results with critical thinking and formulate individual treatment plans for each patient.
\end{abstract}

Keywords: Primary congenital glaucoma, Childhood glaucoma, Goniotomy, Trabeculotomy, Pediatric glaucoma surgery.

How to cite this article: Yu Chan JY, Choy BNK, Alex LK Ng, Shum JWH. Review on the Management of Primary Congenital Glaucoma. J Curr Glaucoma Pract 2015;9(3):92-99.

Source of support: Nil

Conflict of interest: None

\section{INTRODUCTION}

Primary congenital glaucoma (PCG) is rare disease which constitutes a diagnostic and therapeutic challenge to ophthalmologists. The nature of the disease and the challenge it poses both contribute to its potentially devastating impact on a child's vision. In this article, we provide an overview and update on the presentation and treatment options of PCG.

\section{HISTORICAL BACKGROUND}

The first documentation of PCG can be dated back to 400 $\mathrm{BC}$, when hippocrates recognized abnormal enlargement

\footnotetext{
${ }^{1-4}$ Clinical Assistant Professor

${ }^{1-4}$ Department of Ophthalmology, The University of Hong Kong Hong Kong
}

Corresponding Author: Jennifer WH Shum, Clinical Assistant Professor, Department of Ophthalmology, The University of Hong Kong, Hong Kong, Phone: 85239621405, e-mail: jenni101@hku.hk of the eyes in infants. It was not until early 18th century when Berger first linked the elevated intraocular pressure to the enlargement of the globe. In 1869, von Muralt established the classical form of buphthalmos, enlargement of the eyeball, as a form of glaucoma.

Subsequent anatomical dissections performed in the late 1800s and early 1900s pointed toward the malformed angle structure as culprit of PCG. The Manual of Human and Comparative Histology published in 1873 described the angle drainage system, including anatomical structure of Schlemm's canal and Descemet's membrane, referring to them as an anterior lymphatic drainage system. ${ }^{1}$ The Atlas of the Pathological Anatomy of the Eyeball, translated to English from German by William Gowers in 1875, established that angle structure malformation as the culprit for PCG. ${ }^{2}$ The introduction of goniotomy shortly followed in 1938, introduced by Barkan.

\section{CLASSIFICATION}

According to the latest consensus by the World Glaucoma Association, childhood glaucoma is classified as primary or secondary. Primary congenital glaucoma, together with juvenile open-angle glaucoma, constitutes the primary childhood glaucoma. Primary congenital glaucoma can be further subcategorized by its age of onset. Primary congenital glaucoma with onset at birth to less than 1 month old is referred as the neonatal/ newborn onset PCG while late onset PCG is defined as PCG with its onset after 2 years of age. Children suffering from infantile onset PCG would have an onset between neonatal/newborn and late onset glaucoma (i.e. >1-24 months old). ${ }^{3}$

The Hoskins classification identifies the area of dysgenesis (Table 1). Primary congenital glaucoma refers to glaucoma due to isolated trabeculodysgenesis. The angle is maldeveloped, with absence of angle recess and iris often inserted directly onto the trabecular meshwork.

Table 1: Hoskins classification

\section{Trabeculodysgenesis}

Iridotrabeculodysgenesis

- Stromal defects: hypoplasia, hyperplasia

- Anomalous iris vessels

- Structural defects: coloboma, aniridia

Corneotrabeculodysgenesis

- Anomalies, such as Axenfeld's, Rieger's and Peters 


\section{EPIDEMIOLOGY OF PRIMARY CONGENITAL GLAUCOMA}

The incidence of PCG varies across countries and ethnic group. The incidence in the western countries, such as Ireland, Britain and the USA, lies within 1:10,000 to 1:70,000. ${ }^{4-8}$ In Saudi Arabia, Southern India, and among the Gypsy population in Slovakia, the incidence of PCG is significantly higher, quoted between 1:1,250 and 1:3300. ${ }^{4,5,9,10}$ This is thought to be due to the higher incidence of consanguinity. The relationship between consanguinity and higher incidence of PCG is further supported by the statistically significantly higher rate of consanguinity in the parents of PCG than that of the parents of secondary congenital glaucoma patients. ${ }^{8}$ In China, PCG constitutes $5.1 \%$ of all congenital ocular disorders. ${ }^{11}$

The mean age of presentation of PCG occurs at an earlier age in races with higher incidence. It ranges from 3 to 4 months among Asians, Saudi Arabians and Indians to 11 months in Western countries. ${ }^{8,9,12}$ While the incidence and age varies, a slight male predominance is evident in both Asian and Western countries, around 65\%., ${ }^{8,9,12}$

\section{GENETIC ASPECT}

Most PCG cases occur sporadically. They are familial in 10 to $40 \%$ of cases, usually with autosomal recessive inheritance and variable penetrance. ${ }^{5,13}$

The CYP1B1 gene is an autosomal recessive gene located at chromosome $2 \mathrm{p} 21$, and is a culprit gene for PCG. The mutation exhibits variable expressivity, but demonstrates almost complete penetrance. The gene mutation is prevalent in Asian PCG patients, presenting in $70 \%$ of Iran patients, ${ }^{14} 74 \%$ of South Korean patients, ${ }^{15}$ but surprisingly only $20 \%$ of Japanese patients. ${ }^{16}$ The CYP1B1 mutations have also been documented to be present in patients with juvenile open angle glaucoma in Korea and Iran, indicating a possible etiological link between PCG and juvenile open angle glaucoma. ${ }^{14,15}$

\section{PRESENTATION}

Primary congenital glaucoma commonly presents bilaterally, and this is observed across Western and Asian countries alike. ${ }^{8,9}$ The classical triad of symptoms in PCG is epiphora, photophobia and blepharospasm, but could be absent in rare occasions. ${ }^{17}$ In fact, photophobia and blepharospasm is found in only $7.5 \%$ of patients at first presentation, while epiphora is only present in $3.3 \% .{ }^{8}$ Cloudy cornea and buphthalmos account for the most common presenting sign, found in over $40 \%$ of patients. Other presenting symptoms and signs including tearing, ${ }^{18}$ lack of eye contact, facial birthmarks, pupillary abnormalities and nystagmus, but these only account of less than $2.3 \%$ of symptoms at first presentation. ${ }^{8}$

\section{CLINICAL APPROACH TO PRIMARY CONGENITAL GLAUCOMA}

While early diagnosis is crucial, this may be difficult in early stages, which is not made easier by a lack of marked asymmetry. A high index of suspicion is key, followed by detailed history taking and clinical examination, with examination under anesthesia (EUA).

\section{Clinical Examination}

The examination includes checking pupillary reflex, refraction, axial length and keratometry. The quality of the cornea should be examined and presence of corneal edema, scarring and Haab's striae should be documented, preferably with photo or drawing. The horizontal and vertical corneal diameter should be measured. In newborns, the normal horizontal diameter is 9.5 to $10.5 \mathrm{~mm}$ and that in a 1-year-old is 10 to $11.5 \mathrm{~mm}$. Horizontal corneal diameter of over $12 \mathrm{~mm}$ in a newborn should prompt suspicion.

\section{Intraocular Pressure}

The intraocular pressure (IOP) at first presentation and subsequent follow-up should be charted. It is important to note that anesthetic agents are well known to influence the IOP (Table 2), affecting the accuracy of IOP documentation during EUA. Most general anesthetics and central nervous system (CNS) depressants decreases the IOP, except for ketamine, which increases the muscle tone of the extraocular muscles, paradoxically increasing the IOP. Succinylcholine is also known to cause a significant transient increase in IOP, with its peak at 20 to 30 seconds post injection. The underlying mechanism could also be related to its effect on the extraocular muscle, since succinylcholine has been documented to cause extraocular muscle contraction. ${ }^{19,20}$ Chloral hydrate has the least effect on IOP, followed by ketamine.

\section{Gonioscopy}

The angle of healthy infants differs from that of healthy adults, infants have a less distinct Schwalbe's line, less pigmented trabecular meshwork, and a translucent uveal

Table 2: Medications/agents that influence the IOP

\begin{tabular}{lll}
\hline & $\begin{array}{l}\text { Agent decreasing } \\
\text { IOP }\end{array}$ & $\begin{array}{l}\text { Agents increasing } \\
\text { IOP }\end{array}$ \\
\hline Induction agents & $\begin{array}{l}\text { Nitrous oxide } \\
\text { Cyclopropane } \\
\text { Halothane }\end{array}$ & - \\
Muscle relaxants & $\begin{array}{l}\text { Tubocurarine } \\
\text { Gallamine }\end{array}$ & Succinylcholine $^{22}$ \\
General & $\begin{array}{l}\text { Barbiturate } \\
\text { anesthetics }\end{array}$ & Ketamine $^{23}$ \\
& $\begin{array}{l}\text { Morphine } \\
\text { Sevoflurane }\end{array}$ & \\
\hline
\end{tabular}


meshwork, making the junction between scleral spur and ciliary body less clear. The angle in PCG patients differs from that of healthy infants. The iris inserts anteriorly to the trabecular meshwork, resulting in a flat or a concave insertion. Anomalous iris vessels may also be seen as loops branching from the major arterial circle. The peripheral iris may be covered by fine fluffy tissue. ${ }^{25-27}$

\section{Fundoscopy}

Similar to the adult onset open angle glaucoma, the cup disk ratio (CDR) is increased in PCG patients. There are, however, several important differences. In adult onset glaucoma, rim thinning preferentially occurs at the inferior and superior rim due to the abundance of nerve fiber layer in that area. ${ }^{28}$ In PCG, however, the glaucomatous cup enlarges circumferentially, as the scleral canal is uniformly stretched in all directions. ${ }^{29}$ Moreover, reversal of the cup may be possible upon normalization of IOP, due to the high resilience of optic nerve head connective tissue and the elasticity of the lamina cribrosa during infant development. ${ }^{30}$ However, reversal of cupping is not universal, as studies have observed continued thinning of the optic nerve head and retinal nerve fiber layer thinning despite IOP lowering. ${ }^{31}$

\section{TREATMENT}

\section{Medical Management}

Due to significant anatomical anomaly of the anterior drainage angle, medical treatment has a limited role in controlling the IOP in PCG, reducing IOP effectively in less than $10 \%$ of PCG patients. ${ }^{32}$

Table 3 below highlights different classes of antiglaucoma medication and their effects in controlling intraocular pressure in PCG patients. ${ }^{33-35}$

The unfavorable efficacy, high nonresponder rate as well as a lack of long-term safety profile all contribute to the limited use of medical treatment in treatment of PCG. Most parents also find administration of compliance of eye drops in children difficult. The role of medical treatment in PCG is, therefore, generally supportive, with the aim of reducing the cornea opacity before surgery, as an interim treatment while waiting for surgery, or as an adjunct to maximize IOP reduction postoperation.

\section{Surgical Treatment}

The major surgical options for PCG include angle surgery, drainage surgery and cyclophotocoagulation. As the corneal diameter reflects disease severity, it can act as a rough guide to surgery choice. In general, corneal diameter less than $13 \mathrm{~mm}$ represents mild PCG, and surgical options include goniotomy or trabeculotomy. Corneal diameter between 13 and $16 \mathrm{~mm}$ indicates moderate severity, angle surgeries carry a higher chance of failure but may still be attempted. Other options include combined trabeculotomy-trabeculectomy, a traditional trabeculectomy or glaucoma drainage implant. Corneal diameter exceeding $16 \mathrm{~mm}$ indicates severe PCG, which cyclophotocoagulation may be the last resort.

As the manifestation of PCG tends to be more severe and occur in earlier years in non-Caucasians, below we will look into the literature on different surgical methods for PCG with a particular emphasis on non-Caucasian subjects.

\section{Goniotomy}

Goniotomy reduces IOP by cutting into the abnormal trabecular meshwork, allowing the iris to drop posteriorly so as to deepen the angle recess. A clear cornea is a prerequisite. With proper case selection, goniotomy offers promising outcomes. It has been quoted that in $72 \%$ of PCG patients, one goniotomy was sufficient to reach a normal IOP and 88 to $94 \%$ patients would attain a normal IOP in two goniotomies. ${ }^{36-38}$ Predictors of higher success rate are those who present between 1 and 24 months after birth and lower degree of refractive error. ${ }^{36,38}$ The success

Table 3: Effect and side effects of antiglaucoma medications in PCG patients

\begin{tabular}{|c|c|c|c|}
\hline Class & Effect & Side effect & Nota bene \\
\hline Beta blockers & $\begin{array}{l}\text { Fair, no effect in } \\
39-54 \% \text { of patients }\end{array}$ & Possibility of apnea & $\begin{array}{l}\text { To exclude asthma/cardiac } \\
\text { anomaly before use. Check } \\
\text { availability of } 0.25 \% \text { timolol, } \\
\text { which is preferable in children }\end{array}$ \\
\hline Carbonic anhydrase inhibitors & Fair & $\begin{array}{l}\text { Growth suppression, } \\
\text { metabolic acidosis }\end{array}$ & - \\
\hline Prostaglandin analogs & $\begin{array}{l}\text { Poor, no effect in } 50-80 \% \text { of } \\
\text { patients }\end{array}$ & $\begin{array}{l}\text { Mainly local side effects as } \\
\text { observed in adults }\end{array}$ & $\begin{array}{l}\text { Predictors of poor } \\
\text { response include severity } \\
\text { glaucoma and young age of } \\
\text { presentation }\end{array}$ \\
\hline Alpha-2 agonists & - & CNS suppression & Contraindicated in children \\
\hline Parasympathomimetics & Poor & - & $\begin{array}{l}\text { Limited use in pediatric } \\
\text { patient }\end{array}$ \\
\hline
\end{tabular}


rate in the western society is quite high, between 75 and $90 \%$. In comparison, in South East Asian and the Middle East where the age of presentation is much earlier, the quoted success rate of goniotomy drops to approximately $50 \%$. For PCG patients who present at birth to 1 month of age, the success rate after 1 to 2 goniotomies drops to $25 \% .{ }^{36}$

In PCG patients with particular cloudy cornea, which prevents direct visualization of the angle structures, endoscopic goniotomy offers a allowing a direct view of irido-corneal angle and allows angle opening to $300^{\circ} .^{39-41}$ The success rate of endoscopic goniotomy in PCG and secondary developmental glaucoma was quoted to be $50 \%{ }^{42}$

\section{Trabeculotomy}

Trabeculotomy or goniotomy ab externo, was first described in 1960, lowering the IOP through inserting a trabeculotome into the Schlemm's canal, which then tears through trabecular meshwork into the anterior chamber. ${ }^{43}$ Trabeculotomy is feasible in cases where the opaque cornea prevents good visualization of anterior chamber structures. It is also considered to be a more predictable and technically easier surgery. The procedure does not require surgical gonioscopy skills and is, thus, more similar to trabeculectomy, with a less steep learning curve. ${ }^{44}$ However, a direct comparison between goniotomy and trabeculotomy would suffer from selection bias, as trabeculotomy is often performed in more severe cases of glaucoma.

According to a retrospective study conducted in China, IOP less than or equal to $21 \mathrm{~mm} \mathrm{Hg}$ could be achieved in 91 and $87 \%$ of patients 1 and 3 years respectively after trabeculotomy, ${ }^{45}$ which is comparable to Western data in the early 1980 s of 75 to $90 \%$. ${ }^{46,47}$

The $360^{\circ}$ trabeculotomy is one modification of the surgery. Instead of opening approximating one-third of the chamber angle, the $360^{\circ}$ trabeculotomy allows the entire angle to be opened in a single session. This is achieved by threading a 6-0 prolene suture or a lighted canaloplasty device through the Schlemm's canal. A retrospective study comparing goniotomy and $360^{\circ}$ trabeculotomy demonstrated that 92\% PCG patients underwent $360^{\circ}$ trabeculotomy has IOP controlled below $22 \mathrm{~mm} \mathrm{Hg}$ with a single procedure, while only $57.5 \%$ of patients undergoing goniotomy has successful pressure control. The $360^{\circ}$ trabeculotomy also achieves a longer duration of pressure control. ${ }^{48}$

Another modification to traditional trabeculotomy is the utilization of a modified probe tailored to the individual Schlemm's canal curvature. The underlying principle is that patients with varying corneal diameter would have accordingly varying Schlemm canal curvature. Filous et al utilized one of three different probes in a retrospective study, stratifying patients according to their corneal diameters. This modified procedure was able to cause a mean decrease of $47 \%$ in IOP with surgical success achieved in $87 \%$ of the eyes. ${ }^{49}$ However, prospective study comparing traditional trabeculotomy with this modified trabeculotomy is not available.

\section{Combined Trabeculotomy-Trabeculectomy}

In some centers, trabeculotomy is combined with trabeculectomy and is performed as a first line surgery in PCG patients, with trabeculectomy performed after trabeculotomy.

Mandal et al reported an IOP drop of $41.1 \%$ in PCG patients in India after the procedure, with IOP $<21 \mathrm{~mm} \mathrm{Hg}$ maintained at 94.4 and $73 \%$ at the first and third year postsurgery respectively. ${ }^{44}$ Essuman et al demonstrated a success rate of $79 \%$ with combined trabeculotomy-trabeculectomy procedure in a western African population; however, only $44 \%$ patients maintained IOP $<21 \mathrm{~mm} \mathrm{Hg}$ at 1 year of followup. $^{50}$

As for whether combined trabeculotomy-trabeculectomy is superior to either trabeculotomy and trabeculectomy alone, Dietlein et al demonstrated a higher success rate of the combined procedure at 6 and 60 months of follow-up, but the survival analysis failed to demonstrate significant difference in the surgical outcome between the three procedures. ${ }^{51}$ A more recent study, on the other hand, demonstrated no significant difference in mean IOP lowering between groups with trabeculotomy and combined trabeculotomy-trabeculectomy, but statistically significantly higher success rate is achieved in combined surgery compared with trabeculectomy. ${ }^{52}$ One of the possible reason of higher success rate in the combined procedure may be due to the dual outflow pathway after the procedure. ${ }^{53}$

\section{Second Line Treatment}

Following failed angle surgery, ophthalmologists either opt for a second angle surgery, or proceed with a filtration surgery, either a trabeculectomy or a drainage implant.

\section{Trabeculectomy}

Primary trabeculectomy had been a popular procedure in the late 1980s and 1990s, with its success rate varying from 54 to $92.3 \%$ in PCG. ${ }^{54,55}$

In countries where surgical gonio lens are not readily available, primary trabeculectomy is still an effective and popular option. A retrospective study in Nigeria demonstrated statistically significant reduction of corneal haziness and reduction of IOP by $40 \%,{ }^{56}$ while that in 
Egypt is $28.4 \%{ }^{57}$ In a comparison study conducted in China, trabeculectomy has a higher long-term success rate than trabeculotomy, with a less steep decline in the Kaplan-Meier survival analysis. ${ }^{45}$

Problems encountered in performing trabeculectomy in children are multifold: thick tenon, thin sclera, difficulty in identifying the limbus and an exuberant healing response. The success rate of trabeculectomy ranges from 35 to $50 \%$ at 1 year postoperation, ${ }^{58}$ Fulcher et al reviewed the long-term outcome for primary trabeculectomy in PCG, and found a lower success rate in children presenting before 1 year of age. ${ }^{55}$ In view of this, the use of antimetabolites has been gaining popularity.

\section{Antimetabolites}

The use of mitomycin C (MMC) in children has been reported to improve success rates of surgery, quoted as 52 to $82 \% .{ }^{59,60}$ Another study conducted in China yield success rate of $67.4 \%$ with a mean IOP drop of $31 \%$, 1 which is comparable to the international data. As for the optimal concentration, a comparison study shows no statistically significant difference in IOP reduction, success rate or complication between use of 0.4 or $0.2 \mathrm{mg} / \mathrm{ml}$ concentration of topical MMC in refractory PCG patient. ${ }^{62}$

However, not all studies show a favorable outcome. A comparison study between primary trabeculectomy and augmented trabeculectomy with MMC shows no statistically significant difference in IOP lowering, but a higher complication rate with $\mathrm{MMC}$ use, including a higher rate of bleb-related endophthalmitis, ranging from 7 to $17 \%$. ${ }^{5,63}$ As MMC often results in a thin avascular bleb, children are subject to more years of exposure to infection risk, thus resulting in a higher long-term infection rate overall.

Compared with MMC, the role of 5-fluorouracil (5FU) is limited in the pediatric population. Its use often requires additional postoperative injections, which requires additional general anesthesia sessions. ${ }^{63}$ Furthermore, 5FU is significantly less likely to achieve adequate IOP control when compared to MMC. ${ }^{64}$

In addition to trabeculectomy, some centers utilize $5 \mathrm{FU}$ as antimetabolite for combined trabeculotomytrabeculectomy, with a success rate of $65 \%$. However, it is noted that some patients may require up to 19 injections postoperatively, causing repeated risk of general anesthesia to the subject. ${ }^{65}$

\section{Glaucoma Draining Device (GDD)}

Retrospective studies on Ahmed glaucoma valve (AGV) revealed a 28 to $49 \%$ reduction in the mean IOP and a success rate ranging from 63 to $97 \%$ at 1 year. ${ }^{66-68}$ The definition of success is similar across studies, which is defined as absence of serious complications or lost of light perception, with an acceptable IOP with or without the use of medication, thought the acceptable IOP ranges from 18 to $23 \mathrm{~mm} \mathrm{Hg}$ across studies. ${ }^{66-68}$ Hispanic ethnicity and gender female have been reported to be independent predictors for failure of the GDD procedure, but the underlying reason has yet to be identified. ${ }^{68}$

Traditionally, insertion of GDD inevitably involves opening of a scleral flap, which may cause tube-migration related complications. A retrospective study conducted in Mexican children explored the outcomes of AGV implantation through a needle generated scleral tunnel, eliminating the need of a scleral flap. None of the patient had tube extrusion during the 6-month follow-up. ${ }^{69}$ Although the result is not statistically significant due to the small sampling size $(\mathrm{CI} \leq 1.5 \%$ ), the study sheds insight to the alternative methods of GDD insertion.

With regards to the role of MMC application in GDD, a retrospective study studying 31 eyes revealed a success rate 2 years after AGV implantation if MMC was used intraoperatively, during the first 2 years of life (22.15 vs 16.25 months). ${ }^{70}$ It is speculated that MMC stimulates fibrosis along the AGV, leading to decreased success rate.

For studies comparing GDD with augmented trabeculectomy, the majority are retrospective case series which show conflicting results. An age-matched study comparing augmented trabeculectomy with GDD in children under the age of two showed a significantly higher cumulative success rate in the GDD group at 6 years, with the success rate being 53\% in the GDD group and $19 \%$ in the trabeculectomy group respectively. ${ }^{71}$ However, another study targeting older patients between 6 and 17 years of age demonstrated comparable total success rate in the two groups (88\% in AGV and $86 \%$ in MMC-augmented trabeculectomy) and no statistically significant difference in IOP reduction. However, the patients receiving $\mathrm{AGV}$ are two times more likely to be on antiglaucoma medication for IOP control, and the AGV patients have a poorer visual outcome, with a visual acuity drop of three lines (28\% vs $12 \%) .{ }^{72}$ Take note that the above two studies may have selection bias as secondary glaucoma were included, which are known for having a lower trabeculectomy success rate.

Pediatric GDD implantation requires extra considerations. The commonly used GDD include Baerveldt, Ahmed and Molteno implants with size varying from 96 to $250 \mathrm{~mm}^{2}$. The surface area of the implant appears roughly proportional to the pressure-lowering effect. In buphthalmic eyes, the use of adult-sized implants (e.g. AGV model FP7) may be considered. In small nanophthalmic eyes, the use of smaller implants (e.g. AGV model FP8) may be required. ${ }^{73}$ It has been suggested that GDD may be preferable to trabeculectomy when conjunctival scarring is evident, ${ }^{74}$ or in buphthalmic eyes with very thin sclera. ${ }^{66}$ It is hypothesized that as the bleb 
is located more posteriorly in GDD, the long-term risk of infection is, thus, theoretically lower. ${ }^{66}$ However, GDD is associated with more complications that requires reoperation than trabeculectomy ( $46 \%$ vs $13 \%$ ), in particular displacement of tube leading to tube-endothelial touch and tube retraction. ${ }^{68,71}$

\section{Cyclodestructive Procedures}

In general, cyclodestructive procedures are usually reserved until both angle procedures and another surgical modality has failed. The number of sessions required to achieve satisfactory IOP control is difficult to predict. Moreover, chronic inflammation together with relative aqueous under-secretion decreases the success rate of glaucoma drainage surgeries.

The traditional cyclocryotherapy yields a very low success rate of around $30 \%{ }^{75,76}$ This procedure is also associated with more postoperative inflammation, phthisical changes and is usually less preferable. Transscleral diode photocoagulation has a higher success rate, around $50 \%$ at 6 months, with a retreatment rate of $70 \%$ and requiring on average $2.2 \pm 1.3$ sessions. Endoscopic diode cyclodestruction has been described to deliver laser energy more precisely. The success rate after first procedure ranges from 17 to $34 \%$, with mean IOP reduction of 23 to $30 \%$ after two sessions of procedure. ${ }^{77,78}$

Cyclodestructive procedure is known to be associated with multiple severe complications, including retinal detachment, hypotony, progression of vision loss and vitreous hemorrhage. Aphakic patients are in particular more prone to retinal detachment in endoscopic procedures ${ }^{73,77,78}$ Micropulse transscleral diode laser shows promising results with a seemingly better safety profile. ${ }^{79,80}$ Its application and effect in the pediatric population remains to be seen.

\section{CONCLUSION}

Primary congenital glaucoma poses both a diagnostic and therapeutic challenge to the ophthalmologist. Advancement in research and technology has provided a clearer picture on how to tackle the disease, and we have tried to provide an update on PCG management with current evidence. However, due to the low incidence of PCG, studies in the field are usually retrospective, nonrandomized and have a limited sample size. Since the difficulty of management of PCG lies not only in the surgical technique but also in decision-making, clinicians should be aware of the study-design limitations.

\section{REFERENCES}

1. Stricker, S. Manual of human and comparative histology. London: The New Sydenham Society, 1873:3. Vol. 3. pp. 562.
2. Pagenstecher HE, Genth C. Atlas der pathologischen Anatomie des Augenapfels: Atlas of the pathological anatomy of the eyeball. 1875, Wiesburg. 58 bl., 38 pl. (kobberstikk) ill.

3. Weinreb RG, Papadopoulos M, Grigg J, et al. Childhood glaucoma. World glaucoma association consensus series 9 . Amsterdam, The Netherlands: Kugler Publications; 2013.

4. Gencik A, Gencikova A, Ferak V. Population genetical aspects of primary congenital glaucoma. I. Incidence, prevalence, gene frequency, and age of onset. Hum Genet 1982;61(3): 193-197.

5. Gencik A. Epidemiology and genetics of primary congenital glaucoma in Slovakia. Description of a form of primary congenital glaucoma in gypsies with autosomal-recessive inheritance and complete penetrance. Dev Ophthalmol 1989;16:76-115.

6. MacKinnon JR, Giubilato A, Elder JE, Craig JE, Mackey DA. Primary infantile glaucoma in an Australian population. Clin Experiment Ophthalmol 2004 Feb;32(1):14-18.

7. Sarfarazi M, Stoilov I, Schenkman JB. Genetics and biochemistry of primary congenital glaucoma. Ophthalmol Clin North Am 2003 Dec;16(4):543-554, vi.

8. Tamcelik N, Atalay E, Bolukbasi S, Çapar O, Ozkok A. Demographic features of subjects with congenital glaucoma. Indian J Ophthalmol 2014 May;62(5):565-569.

9. Alanazi FF, Song JC, Mousa A, Morales J, Al Shahwan S, Alodhayb S, Al Jadaan I, Al-Turkmani S, Edward DP. Primary and secondary congenital glaucoma: baseline features from a registry at King Khaled Eye Specialist Hospital, Riyadh, Saudi Arabia. Am J Ophthalmol 2013 May;155(5):882-889.

10. Dandona L, Williams JD, Williams BC, Rao GN. Populationbased assessment of childhood blindness in southern India. Arch Ophthalmol 1998 Apr;116(4):545-546.

11. Liu B, Huang W, He M, Zheng Y. An investigation on the causes of blindness and low vision of students in blind school in Guangzhou. Yan Ke Xue Bao 2007 Jun;23(2):117-120.

12. Fung DS, Roensch MA, Kooner KS, Cavanagh HD, Whitson JT. Epidemiology and characteristics of childhood glaucoma: results from the Dallas Glaucoma Registry. Clin Ophthalmol 2013;7:1739-1746.

13. Westerlund E; Københavns universitet. Clinical and genetic studies on the primary glaucoma diseases. Copenhagen: $\mathrm{Nyt}$ Nordisk Forlag; 1947. p. 207.

14. Suri F, Yazdani S, Elahi E. Glaucoma in Iran and contributions of studies in Iran to the understanding of the etiology of glaucoma. J Ophthalmic Vis Res 2015 Jan-Mar;10(1):68-76.

15. Suh W, Kee C. A clinical and molecular genetics study of primary congenital glaucoma in South Korea. Br J Ophthalmol 2012 Nov;96(11):1372-1377.

16. Mashima Y, Suzuki Y, Sergeev Y, Ohtake Y, Tanino T, Kimura I, Miyata H, Aihara M, Tanihara H, Inatani M, et al. Novel cytochrome P4501B1 (CYP1B1) gene mutations in Japanese patients with primary congenital glaucoma. Invest Ophthalmol Vis Sci 2001 Sep;42(10):2211-2216.

17. Girgis NM, FrantzKA. A case of primary congenital glaucoma: a diagnostic dilemma. Optometry 2007 Apr;78(4):167-175.

18. Barsoum-Homsy M, Chevrette L. Incidence and prognosis of childhood glaucoma. A study of 63 cases. Ophthalmol 1986 Oct;93(10):1323-1327.

19. Metz HS, Venkatesh B. Succinylcholine and intraocular pressure. J Pediatr Ophthalmol Strabismus 1981 Jan-Feb;18(1): 12-14. 
20. Dillon JB, Gunter R, Abarwala Taylor DB. Action of succinylcholine on extraocular muscles and intraocular pressure. Anesthesiol 1957 Jan-Feb;18(1):44-49.

21. Varghese C, Chopra SK, Daniel R, Kaur B. Intraocular pressure profile during general anesthesia. Ophthalmic Surg 1990 Dec;21(12):856-859.

22. Kelly RE, Dinner M, Turner LS, Haik B, Abramson DH, Daines P. Succinylcholine increases intraocular pressure in the human eye with the extraocular muscles detached. Anesthesiol 1993 Nov;79(5):948-952.

23. Wadia S, Bhola R, Lorenz D , Padmanabhan P, Gross J, Stevenson M. Ketamine and intraocular pressure in children. Ann Emerg Med 2014 Oct;64(4):385-388.e1.

24. Jones L, Sung V, Lascaratos G, Nagi H, Holder R. Intraocular pressures after ketamine and sevoflurane in children with glaucoma undergoing examination under anaesthesia. Br J Ophthalmol 2010 Jan;94(1):33-35.

25. Papadopoulos M, Edmunds B, Chiang M, Mandal A, Grajewski AL, Khaw PT. Glaucoma Surgery in Children. In: Weinreb RN, Grajewski A, Papadopoulos M, Grigg J, Freedman S, editors. Childhood Glaucoma. WGA Consensus Series-9. Amsterdam: Kugler Publications; 2013. pp 95-134.

26. Faschinger C, Hommer A. Gonioscopy. Berlin Heidelberg: Springer; 2012. pp 25-30.

27. Choplin NT, Lundy DC. Atlas of Glaucoma. 2nd ed. CRC Press; 2007.

28. Jonas JB, Fernandez MC, Sturmer J. Pattern of glaucomatous neuroretinal rim loss. Ophthalmol 1993 Jan;100(1):63-68.

29. Gupta V, James MK, Singh A, Kumar S, Gupta S, Sharma A, Sihota R, Kennedy DJ. Differences in optic disc characteristics of primary congenital glaucoma, Juvenile and adult onset open angle glaucoma patients. J Glaucoma 2014 Sep 26. [Epub ahead of print].

30. Krishnadas R, Ramakrishnan R. Congenital Glaucoma-A Brief Review. J Current Glaucoma Practice 2008 MayAug2008;2(2):17-25.

31. Ely AL, El-Dairi MA, Freedman SF. Cupping reversal in pediatric glaucoma-evaluation of the retinal nerve fiber layer and visual field. Am J Ophthalmol 2014 Nov;158(5): 905-915.

32. Turach ME, Aktan G, Idil A. Medical and surgical aspects of congenital glaucoma. Acta Ophthalmol Scand 1995 Jun;73(3):261-263.

33. Uva MG, Avitabile T, Reibaldi M, Bucolo C, Drago F, Quaranta L, Lionetti E, Longo A. Long-term efficacy of latanoprost in primary congenital glaucoma. Eye (Lond) 2014 Jan;28(1):53-57.

34. Mandal AK, Chakrabarti D. Update on congenital glaucoma. Ind J Ophthalmol 2011 Jan;59 Suppl:S148-157.

35. Maeda-Chubachi T, Chi-Burris K, Simons BD, Freedman SF, Khaw PT, Wirostko B, Yan E; A6111137 Study Group. Comparison of latanoprost and timolol in pediatric glaucoma: A phase 3, 12-week, randomized, double-masked multicenter study. Ophthalmol 2011 Oct;118(10):2014-2021.

36. Shaffer RN. Prognosis of goniotomy in primary infantile glaucoma (trabeculodysgenesis). Trans Am Ophthalmol Soc 1982;80:321-325.

37. Gramer EM, Tausch Kraemer C. Time of diagnosis, reoperations and long-term results of goniotomy in the treatment of primary congenital glaucoma: a clinical study. Int Ophthalmol 1996-1997;20(1-3):117-123.
38. Broughton WL, Parks MM. An analysis of treatment of congenital glaucoma by goniotomy. Am J Ophthalmol 1981;91(5):566-572.

39. Joos KM, Alward WL, Folberg R. Experimental endoscopic goniotomy. A potential treatment for primary infantile glaucoma. Ophthalmol 1993 Jul;100(7):1066-1070.

40. Medow NB, Sauer HL. Endoscopic goniotomy for congenital glaucoma. J Pediatr Ophthalmol Strabismus 1997 JulAug;34(4):258-259.

41. Bayraktar S, Koseoglu T. Endoscopic goniotomy with anterior chamber maintainer: surgical technique and 1-year results. Ophthalmic Surg Lasers 2001 Nov-Dec;32(6):496-502.

42. Kulkarni SV, Damji KF, Fournier AV, Pan I, Hodge WG. Endoscopic goniotomy: early clinical experience in congenital glaucoma. J Glaucoma 2010 Apr-May;19(4):264-269.

43. Smith R. A new technique for opening the canal of Schlemm. Preliminary report. Br J Ophthalmol 1960 Jun;44:370-373.

44. Mandal AK, Bhatia PG, Bhaskar A, Nutheti R. Long-term surgical and visual outcomes in Indian children with developmental glaucoma operated on within 6 months of birth. Ophthalmol 2004;111(2):283-290.

45. Zhang X, Du S, Fan Q, Peng S, Yu M, Ge J. Long-term surgical outcomes of primary congenital glaucoma in China. Clinics (Sao Paulo) 2009;64(6):543-551.

46. Anderson DR. Trabeculotomy compared to goniotomy for glaucoma in children. Ophthalmol 1983 Jul;90(7):805-806.

47. McPherson SD Jr, Berry DP. Goniotomy vs external trabeculotomy for developmental glaucoma. Am J Ophthalmol 1983 Apr;95(4):427-431.

48. Mendicino ME, Lynch MG, Drack A, Beck AD, Harbin T, Pollard Z, Vela MA, Lynn MJ .Long-term surgical and visual outcomes in primary congenital glaucoma: 360 degrees trabeculotomy versus goniotomy. J AAPOS 2000 Aug;4(4): 205-210.

49. Filouš A, Brunová B. Results of the modified trabeculotomy in the treatment of primary congenital glaucoma. J AAPOS 2002 Jun;6(3):182-186.

50. Essuman VA, Braimah IZ, Ndanu TA, Ntim-Amponsah CT. Combined trabeculotomy and trabeculectomy: outcome for primary congenital glaucoma in a West African population. Eye (Lond) 2011 Jan;25(1):77-83.

51. Dietlein TS, Jacobi PC, Krieglstein GK. Prognosis of primary ab externo surgery for primary congenital glaucoma. Br J Ophthalmol 1999 Mar;83(3):317-322.

52. Lawrence SD, Netland PA. Trabeculectomy versus combined trabeculotomy-trabeculectomy in pediatric glaucoma. J Pediatr Ophthalmol Strabismus 2012 Nov-Dec;49(6):359-365.

53. Elder MJ. Combined trabeculotomy-trabeculectomy compared with primary trabeculectomy for congenital glaucoma. Br J Ophthalmol 1994 Oct;78(10):745-748.

54. Debnath SC, Teichmann KD, Salamah K. Trabeculectomy versus trabeculotomy in congenital glaucoma. Br J Ophthalmol 1989 Aug;73(8):608-611.

55. Fulcher T, Chan J, Lanigan B, Bowell R, O'Keefe M. Long-term follow-up of primary trabeculectomy for infantile glaucoma. Br J Ophthalmol 1996 Jun;80(6):499-502.

56. Onwasigwe EN, Ezegwui IR, Onwasigwe CN, Aghaji AE. Management of primary congenital glaucoma by trabeculectomy in Nigeria. Ann Trop Paediatr 2008 Mar;28(1):49-52.

57. Eldaly MA. Pneumatic trabecular bypass versus trabeculotomy in the management of primary congenital glau- 
coma. Graefes Arch Clin Exp Ophthalmol 2014 Jun;252(6): 989-994.

58. Rodrigues AM, Junior AP, Montezano FT, de Arruda Melo PA, Prata J Jr. Comparison between results of trabeculectomy in primary congenital glaucoma with and without the use of mitomycin C. J Glaucoma 2004 Jun;13(3):228-232.

59. Freedman SF, McCormick K, Cox TA. Mitomycin C-augumented trabeculectomy with postoperative wound modulation in pediatric glaucoma. J AAPOS 1999 Apr;3(2): 117-124.

60. Sidoti PA, Belmonte SJ, Liebmann JM, Ritch R. Trabeculectomy with mitomycin- $C$ in the treatment of pediatric glaucomas. Ophthalmol 2000 Mar;107(3):422-429.

61. Chen $\mathrm{Q}, \mathrm{Yu}$ Y, Sun H, Zong Y, Yuan ZL. A retrospective and consecutive study of viscocanalostomy versus trabeculectomy for primary congenital glaucoma. Chin Med J (Engl) 2013;126(8):1418-1424.

62. Ozkiris A, Tamcelik N. Long-term results of trabeculectomy with different concentrations of mitomycin $\mathrm{C}$ in refractory developmental glaucoma. J Pediatr Ophthalmol Strabismus 2005 Mar-Apr;42(2):97-102.

63. Terraciano AJ, Sidoti PA. Management of refractory glaucoma in childhood. Curr Opin Ophthalmol 2002 Apr;13(2):97-102.

64. Snir M, Lusky M, Shalev B, Gaton D, Weinberger D. Mitomycin C and 5-fluorouracil antimetabolite therapy for pediatric glaucoma filtration surgery. Ophthalmic Surg Lasers 2000 Jan-Feb;31(1):31-37.

65. Jalil A, Au L, Khan I, Ashworth J, Lloyd IC, Biswas S. Combined trabeculotomy-trabeculectomy augmented with 5-fluorouracil in paediatric glaucoma. Clin Experiment Ophthalmol 2011 Apr;39(3):207-214.

66. Dave P, Senthil S, Choudhari N, Sekhar GC. Outcomes of Ahmed valve implant following a failed initial trabeculotomy and trabeculectomy in refractory primary congenital glaucoma. Middle East Afr J Ophthalmol 2015 Jan-Mar;22(1):64-68.

67. Razeghinejad MR, Kaffashan S, Nowroozzadeh MH. Results of Ahmed glaucoma valve implantation in primary congenital glaucoma. J AAPOS 2014 Dec;18(6):590-595.

68. Ou Y, Yu F, Law SK, Coleman AL, Caprioli J. Outcomes of Ahmed glaucoma valve implantation in children with primary congenital glaucoma. Arch Ophthalmol 2009 Nov;127(11):1436-1441.

69. Albis-Donado O, Gil-Carrasco F, Romero-Quijada R, Thomas R. Evaluation of Ahmed glaucoma valve implantation through a needle-generated scleral tunnel in Mexican children with glaucoma. Indian J Ophthalmol 2010 SepOct;58(5):365-373.

70. Al-Mobarak F, Khan AO. Two-year survival of Ahmed valve implantation in the first 2 years of life with and without intraoperative mitomycin-C. Ophthalmol 2009 Oct;116(10):1862-1865.

71. Beck AD, Freedman S, Kammer J, Jin J. Aqueous shunt devices compared with trabeculectomy with Mitomycin-C for children in the first two years of life. Am J Ophthalmol 2003 Dec;136(6):994-1000.

72. Hill Rt, Ohanesian R, Voskanyan L, Malayan A, Ohanesian R, Voskanyan L, Malayan A. The Armenian Eye Care Project: surgical outcomes of complicated paediatric glaucoma. Br J Ophthalmol 2003 Jun;87(6):673-676.

73. Tanimoto SA, Brandt JD. Options in pediatric glaucoma after angle surgery has failed. Curr Opin Ophthalmol 2006 Apr;17(2):132-137.

74. Ishida K, Mandal AK, Netland PA. Glaucoma drainage implants in pediatric patients. Ophthalmol Clin North Am 2005 Sep;18(3):431-442, vii.

75. Al Faran MF, Tomey KF, al Mutlaq FA. Cyclocryotherapy in selected cases of congenital glaucoma. Ophthalmic Surg 1990 Nov;21(11):794-798.

76. Wagle NS, Freedman SF, Buckley EG, Davis JS, Biglan AW. Long-term outcome of cyclocryotherapy for refractory pediatric glaucoma. Ophthalmol 1998 Oct;105(10): 1921-1926.

77. Al-Haddad CE, Freedman SF. Endoscopic laser cyclophotocoagulation in pediatric glaucoma with corneal opacities. J AAPOS 2007 Feb;11(1):23-28.

78. Neely DE, Plager DA. Endocyclophotocoagulation for management of difficult pediatric glaucomas. J AAPOS 2001 Aug;5(4):221-229.

79. Aquino MC, Barton K, Tan AM, Sng C, Li X, Loon SC, Chew PT. Micropulse versus continuous wave transscleral diode cyclophotocoagulation in refractory glaucoma: a randomized exploratory study. Clin Experiment Ophthalmol 2015 Jan-Feb;43(1):40-46.

80. Tan AM, Chockalingam M, Aquino MC, Lim ZI, See JL, Chew PT. Micropulse transscleral diode laser cyclophotocoagulation in the treatment of refractory glaucoma. Clin Experiment Ophthalmol 2010 Apr;38(3):266-272. 